\title{
Omphalocele-Exstrophy-Imperforate Anus-Spinal Defects (OEIS) Complex: About Two Cases and Review
}

\author{
Raja Briki, Ons Cherif*, Mouna Derouich, Rym Zgaya, Anouar Chaieb and Mohamed Bibi \\ Department of Gynecology and Obstetrics, Farhat Hached University Hospital, Tunisia
}

Submission: October 01, 2018; Published: October 11, 2018

*Corresponding author: Ons Cherif, Department of Gynecology and Obstetrics, Farhat Hached University Hospital, Sousse, Tunisia, Email: ons.cherifb@gmail.com

\begin{abstract}
OEIS complex (Omphalocele, Exstrophy of the cloaca or the bladder, Imperforate anus, and Spine abnormalities) is a rare defect, without obvious etiology in most cases. We report two cases of OEIS complex, and we propose to review the different causes, the etiopathogenesis as well as the clinical characteristics of this pathological entity by referring to a recent review of the literature.

Keywords: Omphalocele; Exstrophy; Imperforate anus; Spine; Infraumbilical mesenchyme, Cloacal septum; Ultrasonography
\end{abstract}

\section{Introduction}

Omphalocele, exstrophy of cloaca or bladder, imperforate anus and spinal defect (OEIS) complex is a clinical entity first described by Carey et al. [1]. It's a rare congenital defect. The most recent studies report an incidence of $1 / 200000$ [2] to $1 / 100000$ live births [3].

The OEIS complex is usually sporadic and arises from a single localized defect in the early development of the mesoderm that will later contribute to infraumbilical mesenchyme, cloacal septum, and caudal vertebrae [4]. It has no evident etiology. We propose to analyze the different manifestations of the OEIS complex through two observations and a recent review of literature.

\section{Clinical Cases}

\section{Observation 1}

Mrs I.J, aged 34, was presented at 32 weeks gestation for obstetric ultrasound. Her pregnancy was spontaneous, with normal unwinding. Ultrasonography of the 3rd trimester showed an omphalocele, a short and narrow thorax, lumbar and sacral vertebral abnormalities associated with myelomeningocele, deformity of the lower limbs with no visualization of the bladder.

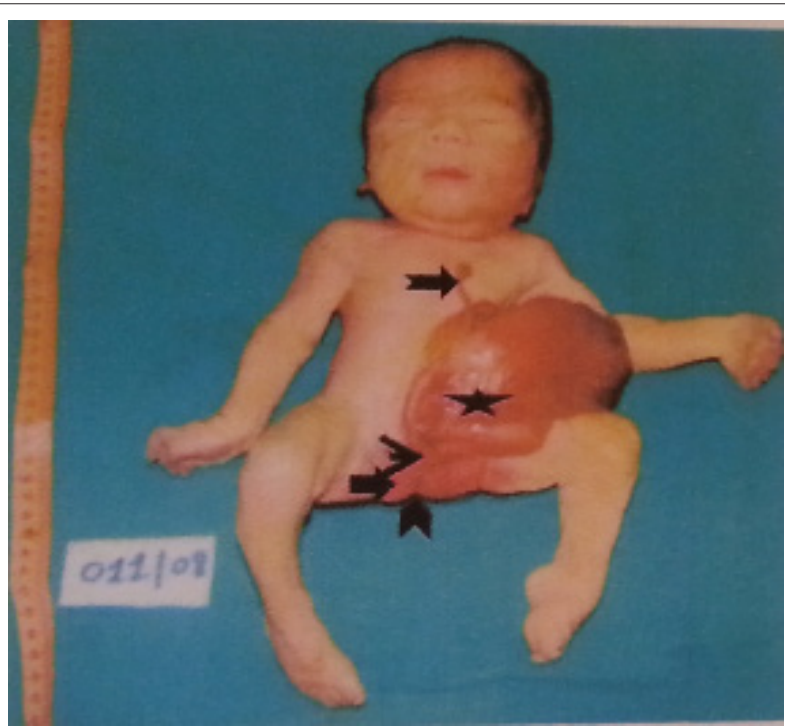

Figure 1: Important omphalocele + bladder 's exstrophy + imperforate anus + two empty hemi-scrotums. 
A male child was born vaginally at 34 weeks gestational age. The birth weight was $2050 \mathrm{~g}$, with normal length and head circumference. Multiple anomalies were present at birth including omphalocele, bladder's exstrophy, imperforate anus, and empty hemi-scrotums with prominent rugated labioscrotal folds (Figure
1). Facial anomalies were observed, including low set ears, deep set eyes, epicanthal folds, and a flat nasal bridge (Figure 2). A skeletal radiograph of the newborn revealed abnormalities in the development of the sacrum (hypogenesis) and the symphysis pubis (Figure 3).

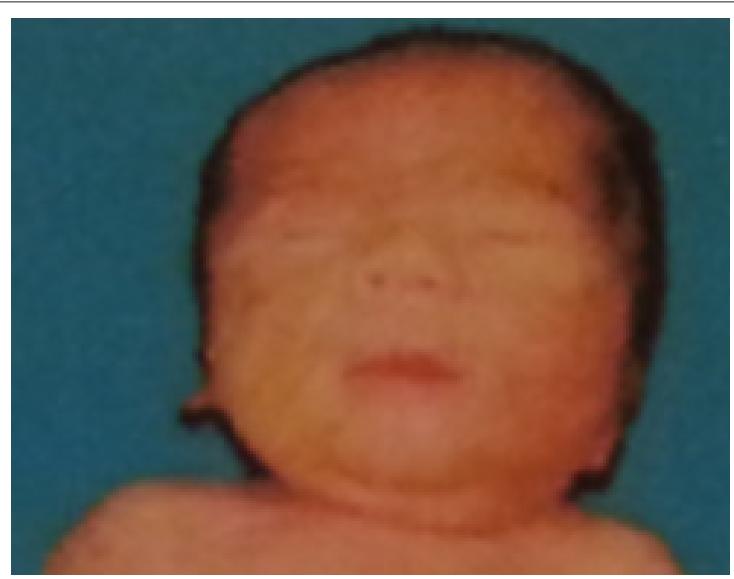

Figure 2: Facial anomalies with low set ears + deep set eyes + epicanthal folds + flat nasal bridge.

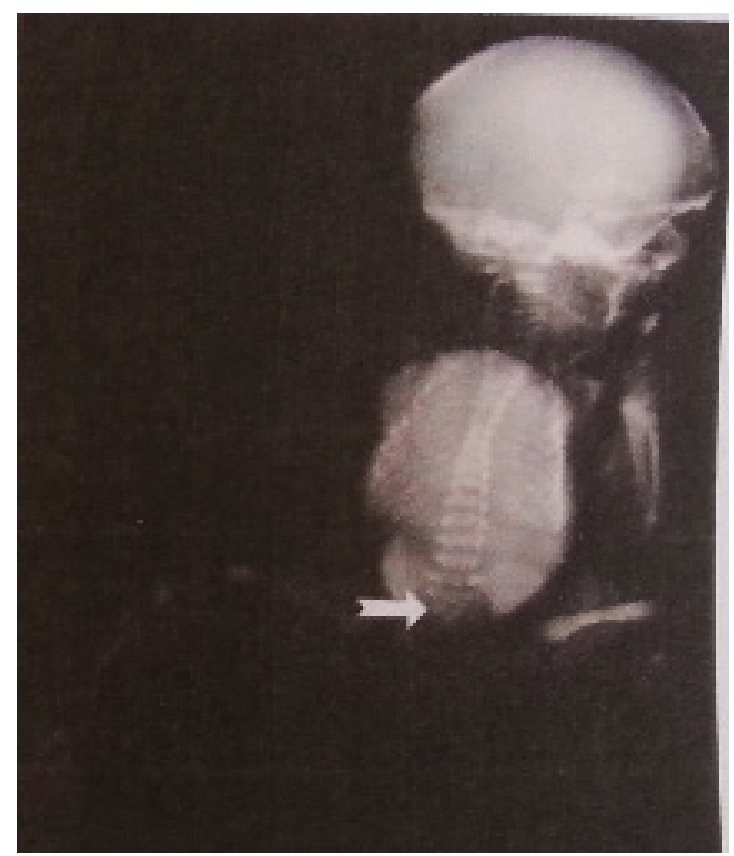

Figure 3: Skeletal radiograph showing abnormalities in the development of the sacrum.

\section{Observation 2}

Mrs. S.T, aged 28, was referred for discovery, on morphological ultrasound at 23 weeks of amenorrhea, of an omphalocele. Ultrasound showed a large omphalocele containing the liver, spleen, gastrointestinal tract and heart. The bladder had not been visualized. The kidneys were normal but there was significant bilateral pelvic-calyx dilatation. The amniotic fluid was in diminished quantity. There was myelomeningocele with abnormalities of the lumbar and sacral vertebrae. Both lower limbs were deformed in equinovarus varus foot. The diagnosis was an OEIS syndrome, and a medical interruption of the pregnancy, after discussion and following parental consent, was practiced.

\section{Discussion}

The OEIS complex is, in the majority of cases, sporadic, without evident cause. However, some reported cases had in their family index cases with similar malformations or chromosomal abnormalities such as monosomy 1p36 [5].

The clinical manifestations of OEIS complex documented in literature $[2,3,6,7]$ associate gastrointestinal abnormalities (omphalocele, imperforate anus, duplicated colon or intestine, intestinal malrotation, anal atresia, anteriorly placed anus, fistulas, intestinal atresia), urinary anomalies (cloacal exstrophy, renal agenesis or hypoplastic kidney, pelvic kidney, duplicated 
collecting system, hydroureter or hydronephrosis), genital abnormalities (ambiguous genitalia, small penis and epispadias, abnormal or absent scrotum, cryptorchidism, hypoplastic labia, widely separated labioscrotal folds, bifid uterus, clitoris and labia minora splayed to one side, bifid clitoris, vaginal remnants, absent uterus, vesico-vaginal or recto-vaginal fistula, hypoplastic fallopian tube), skeletal spine abnormalities (hemivertebrae, sacral anomalies with hypogenesis or segmentation), limb abnormalities (arthrogryposis, syndactyly, thumb hypoplasia, club feet, dysplastic or hypoplastic lower extremity, symphysis pubis diastasis, congenital hip dislocation), and neurologic anomalies (tethered cord, spina bifida, Chiari malformation, hydrocephalus, developmental delay).

An accurate prenatal diagnosis of OEIS complex and associated malformations is important for the detailed counseling of the family as well as appropriate perinatal management by the obstetricians, pediatric surgeons, urologists, neurosurgeons, and neonatologists.

The poor prognosis and disappointing results of postnatal surgical treatment should indicate detailed genetic counseling and good awareness in perinatal management.

\section{Conclusion}

Antenatal diagnosis of OEIS complex is so important for family counseling as well as adapted perinatal management by obstetricians, neonatologists, pediatric surgeons, pediatric urologists, pediatric orthopedic surgeons and pediatric neurosurgeons.

\section{References}

1. Carey JC, Greenbaum B, Hall BD (1978) The OEIS complex (omphalocele, exstrophy, imperforate anus, spinal defects). Birth Defects Orig Artic Ser 14(6B): 253-263.

2. Martinez-Frias ML, Bermejo E, Rodriguez-Pinilla E, Frias JL (2001) Exstrophy of the cloaca and exstrophy of the bladder: Two different expressions of a primary developmental field defect. Am J Med Genet 99(4): 261-269.

3. Keppler-Noreuil K, Gorton S, Foo F, Yankowitz J, Keegan C (2007) Prenatal ascertainment of OEIS complex/cloacal exstrophy-15 new cases and literature review. Am J Med Genet 143A(18): 2122-2128.

4. Chen CP, Shih SL, Liu FF, Jan SW, Jeng CJ, et al. (1997) Perinatal features of omphalocele-exstrophy-imperforate anus-spinal defects (OEIS complex) associated with large meningomyeloceles and severe limb defects. Am J Perinatol 14(5): 275-279.

5. El-Hattab AW, Skorupski JC, Hsieh MH, Breman AM, Patel A, et al. (2009) OEIS complex associated with chromosome 1p36 deletion: A case report and review. Am J Med Genet 152A(2): 504-511.

6. Keppler-Noreuil KM (2001) OEIS complex (omphalocele-exstrophyimperforate anus-spinal defects): A review of 14 cases. Am J Med Genet 99(4): 271-279.

7. Meglin AJ, Balotin RJ, Jelinek JS, Fishman EK, Jeffs RD, et al. (1990) Cloacal exstrophy: Radiologic findings in 13 patients. Am J Roentgenol 155(6): 1267-1272.

\section{Your next submission with Juniper Publishers will reach you the below assets}

- Quality Editorial service

- Swift Peer Review

- Reprints availability

- E-prints Service

- Manuscript Podcast for convenient understanding

- Global attainment for your research

- Manuscript accessibility in different formats

( Pdf, E-pub, Full Text, Audio)

- Unceasing customer service

Track the below URL for one-step submission https://juniperpublishers.com/online-submission.php 